July 29,2012

\title{
Lessons from the Economics of Crime
}

\author{
Philip J. Cook, Sanford School of Public Policy, Duke University \\ Stephen Machin, Department of Economics, University College, London \\ Olivier Marie, Research Centre for Education and the Labour Market, Maastricht \\ University
}

Giovanni Mastrobuoni, Collegio Carlo Alberto, University of Turin

It is not unusual these days to have a group of economists gather to discuss their research on crime. In Europe and the Americas, a critical mass of academic economists have specialized in the study of crime and its control, and there is now a steady flow of economics doctoral dissertations on this topic. As we near the $50^{\text {th }}$ anniversary of Gary Becker's seminal contribution to this field (Becker, 1968), it is fair to say that the economics of crime is no longer a "fringe" topic, but part of the standard portfolio that makes up economics.

Among the markers of progress are these:

- The National Bureau of Economic Research (NBER) created a working group on crime that has had regular meetings since 2007 and published an edited conference volume in 2011 (Cook, Ludwig, and McCrary);

- A new organization within LACEA (the Latin American and Caribbean Economic Association), with the acronym AL CAPONE (The America Latina Crime and Policy Network) held its first annual meeting in $2011 ;^{1}$

- The Transatlantic Workshop on the Economics of Crime has been running annually since 20009 (Paris 2009, Bonn 2010, Torino 2011, Rotterdam 2012);

- John Jay College of Criminal Justice in New York City recently added an economics department, while think tanks like the Vera Institute of Justice and the Urban Institute are producing cost-benefit assessments of crime-control programs;

- Leading economics journals in Britain and the United States have been publishing crime papers on a regular basis for 40 years, and criminology journals have recently begun publishing articles authored by economists;

\footnotetext{
${ }^{1}$ The principals in the formation of AL CAPONE had earlier produced an edited collection through NBER (DiTella, Edwards, and Schargrodsky 2010).
} 
- The conference that produced the papers in this volume, sponsored by CESifo as part of its annual meeting in Venice (2011), is one of several similar meetings in Europe in recent years that, like the NBER crime group and AL CAPONE, are helping create an international network of scholars.

Of course, the social-scientific study of crime was well established by the time of Gary Becker's contribution. Prior to that, from the 1920s onward, the dominant disciplines were sociology and psychology, and that continued to be the case as criminology departments and schools were established in the post-war period. Becker chose to bypass rather than engage with that tradition, saying "... a useful theory of criminal behavior can dispense with special theories of anomie, psychological inadequacies, or inheritance of special traits and simply extend the economist's analysis of choice (p. 170)." With this bit of disciplinary imperialism as a guide, subsequent economics contributions tended to adopt the view that crime research was virgin territory, scarcely inhabited. Economists were initially not so welcome in criminology, and for the most part were unconcerned about that fact, feeling that they had little to learn from the "natives." Recently that separation between economics and criminology has begun to break down, a welcome trend that can be traced in part to the growth of multi-disciplinary public-policy programs and think tanks in the United States. ${ }^{2}$

What have the economists contributed to the study of criminal behavior and crime control? In what follows, to motivate and describe the contributions to this edited volume, we discuss three domains:

- A normative framework for evaluating criminal law and crime prevention, and the application of sophisticated quantitative methods to analyze the causes of crime and the effects of crime-control measures in this framework;

- The conception of criminal behavior as individual choice, influenced by perceived consequences;

- The aggregation of individual choices to a systems framework for understanding crime rates and patterns.

The papers in this volume are informed by and contribute to all of these domains.

A. Policy choice and a normative framework

During the tumultuous years of the 1960s, with riots in the cities and escalating rates of crime and drug abuse, the U.S. Congress created several high profile commissions to assess the underlying problems and recommend effective reforms. When these commissions turned to the

\footnotetext{
${ }^{2}$ Most of the U.S. academic economists for whom crime is a long-term specialty have appointments in public policy schools or other interdisciplinary units (including law schools).
} 
prominent criminologists of the day, they offered their opinions but had little in the way of relevant evidence. The political scientist James Q. Wilson was a critical observer of criminology at the time and observed that its sociological orientation did not lend itself to evidence-based policy recommendations (Wilson 1975). Crime was understood to be caused by culture and social structure. An analysis of these "root causes" of crime provided little guidance for policymakers, whose ability to change structural aspects of society was very limited. Moreover, the sociologists were highly skeptical of the deterrence mechanism, denying or disregarding a role for the criminal justice system in controlling crime. In Great Britain the disconnect between criminology and policy was perhaps even greater, since the dominant ethos dictated against policy engagement, in part because of its heavier focus on the social context of crime (Muncie, 2005).

Among the social sciences, economics tends to be best suited for addressing issues relevant to policy design. The economic model presumes that observed behavior is not the inevitable result of underlying social conditions, but rather results from individual choices influenced by perceived consequences. If government policy can change those consequences, then behavior change will follow. Furthermore, uniquely among the social and behavioral sciences, economic science incorporates a well-developed normative framework that defines the public interest and lends itself to policy prescription.

Indeed, Becker's contribution was primarily in the normative realm. He pointed out that the social costs associated with crime are the sum of the direct costs of victimization (and the threat of victimization) and the indirect costs of efforts to control and prevent crime. If the goal is to minimize total social costs, then the optimal amount of crime is unlikely to be zero, since at some point the marginal costs of additional prevention will exceed the marginal benefit of an additional reduction in crime.

This simple and profound insight is relevant today in assessing progress against the crime "problem" in Western countries. Over the last 20 years crime rates have been relatively stable or falling in most European countries and declining in the United States (Buonanno et al. 2011). In the United States the decline has been associated with an increase in public and private expenditure on prevention and control (Cook and Ludwig 2011), most notably (but by no means limited to) in the form of the burgeoning prison population. Whether the total social costs have been going down is thus an open question, since the increasing costs of control and avoidance may make up for the falling direct costs.

The normative framework also provides guidance for evaluating specific interventions. The economic question is not limited to "what works?" in crime control, but "what is worthwhile?" Cost-benefit analysis provides a set of rules for answering that question, and more generally encourages a comprehensive approach to evaluation. An example in this volume is Emily 
Owen's article on the COPS program, which provides federal funding in the United States to some jurisdictions for hiring additional police officers. The question of whether the additional officers had an effect on crime rates is surely of interest, but if the answer is yes there remains the question of whether it passes the cost-benefit test. She expands the discussion to consider the arrest rate, since arrests and subsequent court processing generate public costs. (The fact that she finds that arrest rates actually decline along with crime rates strengthens the case that COPS is cost-beneficial. ${ }^{3}$ )

The economist's normative framework also provides guidance on the appropriate scope of the criminal law. The tradition of consumer sovereignty, informed by the utilitarian perspective that measures the public interest as the sum of individual preferences, engenders a skeptical view of sumptuary laws of all kinds. The chapter in this volume on drug policy by John Donohue notes that Nobel laureate Milton Friedman was a passionate advocate for legalization of marijuana, heroin, and other drugs, in part because of his belief that individual adults were the best judge of their own best interests. That perspective does not settle the issue for most observers, including most economists; for one thing, commodities that are both harmful to the user and addictive (such as heroin, crack-cocaine, alcohol and tobacco) pose a particularly stringent test of the utilitarian perspective. Do we really believe that youths who are deciding to shoot up or smoke have their own best lifetime interests in mind? If yes, then the damage they end up doing to their health and careers should not be a concern of government policy. Even starting with a more equivocal view, the economic normative framework helps organize a comprehensive accounting scheme for determining which costs and benefits to consider. Given current practice, the costs of criminalization and enforcement loom large, which motivates a search for more efficient means of controlling use and abuse.

Evaluation and study of criminal activities in this normative framework has recently been greatly enhanced by two phenomena which economists of crime have been the first to fully integrate into their research approach: (i) the significant improvement in data availability and data quality; and (ii) implementation of creative statistical methods to directly study causal relations in crime and crime control.

Increased access to high quality data has greatly improved the potential to empirically, and more accurately, study the link between criminal participation and other factors that have theoretically been identified to influence its prevalence. Recorded police crime statistics have historically been one of the main sources of data used by researchers. It is very useful to look at crime rates over time and across areas when studying if these have been affected by the introduction of a localized policy initiative. Arrests, and other CJS data, have also been extensively exploited

\footnotetext{
${ }^{3}$ This is also what Machin and Marie (2011) observed when exploring the mechanisms behind the large drops in robberies they observed after police funding was raised in certain areas of England and Wales (but not in others) to combat street crime.
} 
since they has the advantage of providing some basic information on the characteristics of the offenders (e.g. age, gender, ethnicity). This enables studies to focuses on the offending rates of certain population sub-groups of interest that may react differently to stimuli that may affectcriminal participation. Researchers can also consider how certain policies or exogenous shocks affected the crime rates of particular cohorts or of individuals in certain areas using arrest information.

The latest development in data collection has been the matching of individual administrative criminal datasets with other data sources containing information on offender characteristics such as education and employment of very large samples of the population. This will for example enable research into the complex dynamics between labour market opportunities and criminal participation at the individual level to emerge in the very near future. ${ }^{4}$

The papers in this volume use or make reference to the very wide array of data sources available across the world to carry out research into the causes of offending used today. Over and above data related advances, they also all emphasise the importance of a solid and coherent methodology to test the validity of the normative framework.

The other important feature of the application of the normative framework has been the contribution by economists of using advanced and innovative statistical methods. The first wave of econometric studies of deterrence using aggregate data (Ehrlich 1973; Sjoquist 1973; CarrHill and Stern 1973) utilized complex multi-equation multivariate models estimated by two-stage least squares - at about the same time that criminologists were publishing the results of simple correlations on the same topic. Still, the first wave of econometric research was effectively critiqued by an expert panel of the National Research Council (Blumstein, Cohen and Nagin 1978) and others (Cook 1977). The essential problem was the lack of plausibly exogenous instrumental variables on which to anchor a causal analysis of non-experimental data. As economics has increasingly embraced the use of natural and field experiments, economists have produced more robust findings on the causes of crime. One of the leaders in the creative use of plausibly exogenous variation to identify crime causation is Stephen Levitt, whose research (and emergence as a celebrity, thanks to his book Freakonomics) has done much to inspire subsequent cohorts of graduate students in economics (Ayres and Levitt 1998; Levitt, 1996, 1997, 2004 2005)

\footnotetext{
${ }^{44}$ In the past only a couple of papers, Grogger (1995) and Kling (2005), have used individually matched data to explore this relationship and this was focused on a relatively small population only composed of offenders. Today certain researchers in Northern European countries are developing national level matched datasets covering a large proportion of the entire population.
} 
When it comes to empirical methods, the leading edge for economics and criminology has converged in recent years. "Experimental criminology" is thriving and cuts across disciplines." In this volume, the chapter by Jens Ludwig, Jeffrey R. Kling, and Sendhil Mullainathan discusses the agenda for policy experiments in crime control. Their theme is relevant to experimental work in criminology as well as economics. The ultimate objective of policy experiments is to discover what works and what is worthwhile. Testing innovative interventions through field experiments is vitally important if we are to have the possibility of evidence-based policy. However, the authors point out that policies or programs are usually quite complex, and their effectiveness may be mediated by a variety of factors specific to time and place.

What we can learn from a policy experiment, then, may be less than meets the eye - even a clear demonstration that a complex program implemented by a particular agency in a given environment is cost-effective (in comparison with the status quo) may leave considerable uncertainty about whether a similar policy would be effective, let alone worthwhile, if implemented by another agency in a different jurisdiction. For that reason it is important to focus the empirical research agenda on the basic mechanisms that influence crime rates. For example, if it can be established that the deterrent effect of punishment is more sensitive to the probability of punishment than the severity of punishment (as many of us suspect), then policy innovations that increase the probability of punishment will have a better prognosis than those that increase the severity of punishment. The authors point out that there may be tradeoffs in experimental design between whether the intervention is realistic (something that might be implemented) and isolating a particular mechanism for evaluation. Nevertheless, causal research focused on basic mechanism may produce generalizable knowledge of the sort most needed in policy design.

\section{B. Crime as a rational choice}

A simplistic but common understanding of crime is that the population can be divided neatly into two groups, good guys and bad guys. In this view, the bad guys commit crime unless they are incapacitated, and the good guys are reliably law abiding. This view had particular sway as an explanation for the surge of youth violence in the United States during the decade beginning in 1984. The sociologist John DiIulio, together with William Bennett (a member of President Reagan's cabinet), asserted that the surge was due to the growing ranks of remorseless killers, "superpredators" who grew up in poor, violence-ridden neighborhoods and broken homes. In effect, then, the claim was that the surge in murder was the direct result of a surge in the number of bad guys (Cook and Laub 2002). The only recourse appeared to be locking up as many of these superpredators as possible, and indeed most states changed their laws to facilitate

\footnotetext{
${ }^{5}$ For example: The Journal of Experimental Criminology began publishing in 2005, under David Weisburd's direction. Cambridge University created the Jerry Lee Centre of Experimental Criminology in 2007 under the leadership of Lawrence Sherman.
} 
sentencing teenage felons to long prison terms (Dodge 2008). As it turned out there was no scientific basis for the "superpredator" claim. The evidence points strongly to environmental factors, and the leading contender in that regard is the crack epidemic. However, the "superpredator" claim was appealing in its simplicity and its veneer of social science.

The economic model of crime shifts the focus from character to the choices that are available to the individual. While certain aspects of character (or "preferences") are surely not irrelevant, criminal activity represents a choice, or set of choices, that is available to everyone. The choice of whether to commit crime is driven by the consequences, which differ among individuals depending on the opportunities available to them. For example, a school dropout will have relatively poor opportunities to earn a legitimate living, but lack of schooling is no barrier to larceny or robbery. For that reason alone we expect dropouts to be over-represented among active criminals. One type of formal economic model has treated criminal opportunities as gambles, with a payoff if successful and some probability of failure entailing arrest and punishment. If the threatened punishment includes a prison term, or stigma that reduces access to good jobs, then the effect will be greater for those with good legitimate prospects. An alternative approach has modeled crime as analogous to work, an activity that competes in use of time with other activities (Ehrlich 1973), but with a risky set of consequences.

This perspective leads naturally to a presumption of deterability - that crime rates will be inversely related to the likelihood and severity of punishment. However, the economic model also incorporates the idea that programs to improve legitimate opportunities may have a deterrent effect through increasing the opportunity cost of time spent in criminal activity or in prison. People with something to lose are less likely to view criminal participation as attractive and crime reductions can therefore be achieved by influencing the life opportunities of potential offenders. Some recent papers, Lochner and Moretti (2004), Machin et al. (2011) and Hjalmarsson et al. (2012), have for example shown that education has a large crime reducing effect on cohorts of individuals that were forced to stay longer at school because of changes in minimum school leaving age legislation.

So what happened to cause the epidemic increase in youth violence in the United States during the crack era? As noted, an explanation in terms of the number of "bad guys" does not fit the basic facts. ${ }^{6}$ The economic perspective encourages an explanation in terms of an upward shift in the payoff to gun violence. That may indeed have been the case, as the introduction of crack into cities had the effect of disrupting established drug distribution networks and creating new contests over turf that in the United States (unlike other countries).

\footnotetext{
${ }^{6}$ For example, Cook and Laub (1998) show that the cohorts of youths who were caught up in the epidemic of violence between 1984 and 1993 exhibited normal rates of crime involvement prior to the epidemic, and dropped back toward the normal level following the crest of the epidemic. The extreme volatility of homicide rates for young African American men during that period also belies an explanation in terms of long-term trends in the conditions of their upbringing.
} 
The economic focus on choices and consequences does not preclude the possibility that character (or what economists are inclined to call "preferences") is also important in influencing criminal involvement. The potential importance of changing preferences is suggested by the very strong relationship between criminal involvement and age; the age profile of crime commission declines steeply after age 20 or so, a pattern that may reasonably be interpreted as reflecting changing preferences (brain development, hormones) associated with the aging process -- although aging is not a well-controlled experiment. More specifically, some crime reduction programs focus directly on changing preferences, for example therapeutic interventions intended to reduce craving for illicit drugs.

Efforts to rehabilitate criminals may focus either on increasing the quality of legitimate opportunities (typically by improving human capital or clearing away barriers to earning a legitimate living), or on changing cognitive processes and capacities, such as self-control, empathy, and rationalization. While there have been myriad evaluations of specific programming intended to reduce recidivism rates, there remains considerable uncertainty about the overall effect of a spell of imprisonment on subsequent behavior. Aurélie Ouss reviews the contributions of economists to this literature, finding a surprising agreement that longer prison terms tend to reduce recidivism rates. Another chapter, by Stefan Pichler and Daniel Rőmer, presents new results on recidivism rates by German youths age 18-20, finding that those who are sentenced as juveniles tend to have higher recidivism rates than those who are sentenced as adults (with greater use of prison). The mechanism by which prison time affects post-release recidivism rates is not clear. It is possible that the actual experience of incarceration changes perceptions about the likelihood or severity of future sanctions. But there are numerous other ways in which the regimentation and social interactions of prison life might influence character or post-release opportunity.

Crime as a rational choice has recently been applied to understand the behavioural response of anever wider variety of agents facing criminal participation decisions and of the institutions who aim to prevent offending. In his chapter to this volume, Mikael Priks argues that this framing also serves to explain the activities of certain sports fans of who are involved in violent activitieswhich may at first appear relatively puzzling. He discusses how his research into what he labels 'hooliganomics' shows that agents affiliated to sports booster clubs are as any rational agents and will respond to (dis)incentives influencing crime participation.. He makes here the interesting argument that the club may provide some check on its members' hooliganism, depending on the composition of membership. If the hooliganism-prone members come to dominate, then the internal regulation of behavior may erode. ${ }^{7}$

\footnotetext{
${ }^{7}$ The ability of street gangs in the United States to regulate gun use by their members was exploited by criminaljustice authorities in Boston's Operation Ceasefire (Braga, Kennedy, Piehl 1997), and has been reported in ethnographic work with gangs in Chicago (Cook et al. 2007).
} 


\section{Feedbacks and interactions}

Economics is a social science. The theory of individual behavior serves as a building block for a theory of aggregate outcomes: the wealth of nations, or quantity and price in a specific market. The aggregation of individual choices in the context of a complex system can produce some surprising results - for example, that in a competitive industry, the individual producers' pursuit of profit maximization drives down prices to the point where there is no profit to be made. With respect to crime patterns, there can also be counter-intuitive results. For example, it is interesting to observe that vulnerable population groups sometimes have relatively low crime victimization rates; the "little old ladies" living in the inner city are rarely robbed because they have adapted to the threat by hiding out at home behind locked doors (Cook 1986).

The interacting systems that connect crime-related choices by individuals to aggregate outcomes (aggregate rates and patterns) have not been fully worked out by economists, but the literature provides a start on this project. Criminal activity may be viewed as produced by individuals (active criminals) at a rate that is limited by the activities of the criminal justice system and private security measures. ${ }^{8}$ The electorate chooses through the political process how many public resources to devote to the criminal justice system, and private households and businesses make myriad individual choices about how much private effort to devote to crime prevention and avoidance. A further complication is that the effectiveness of the criminal justice system is very much dependent on private (often voluntary) inputs, such as reporting crimes and providing information and testimony during investigations.

There are at least three noteworthy feedback loops in this system. First, the capacity of the criminal justice system to control crime may be diluted by an exogenous increase in crime rates, which then causes a reduction in the likelihood or severity of punishment - resulting in further increases in the crime rate. Second, an exogenous increase in the crime rate may raise the political salience of crime, leading to increased criminal-justice budgets and stricter sentencing, which may then rein in the crime rate. And third, an exogenous increase in crime may induce greater private efforts at prevention and avoidance of criminal victimization, including actions ranging from locking up valuables and carrying a weapon, to hiring guards or relocating commercial activity to safer neighborhoods. These private responses can in turn either exacerbate or curtail the crime increase, depending on the specifics. The first two loops of this conceptualization were incorporated in the econometric models of the first wave of modern crime studies (cited above). The third loop, that makes private prevention efforts endogenous,

\footnotetext{
${ }^{8}$ Private actions have great potential to influence crime rates and patterns, and increasing private security expenditures and technology, combined with an extraordinary increase in crime reporting, deserve part of the credit for the crime drop since the mid-1990s (Cook and MacDonald 2011).
} 
was introduced soon thereafter (Ehrlich 1981; Cook 1986), but has been largely neglected in the economics literature.

Observed crime rates are thus the outcome of a complex interactive system, which may frustrate the goal of making unambiguous predictions, or even keeping track of all the relevant mechanisms. A case in point is understanding or predicting how immigration affects crime rates. The first pass might be to ask "are these immigrants law-abiding people?" (a question that harks back to the notion, discussed above, that crime rates are proportional to the number of bad people). A more sophisticated inquiry would attempt to assess the public and private resources available for crime control and prevention in immigrant communities, and the likely spillovers to other communities. (Note that the immigrants are both users and contributors to these resources.) A still more comprehensive analysis would include the effects of the immigrant groups on labor markets (typically at the low-wage end of the spectrum), since immigrants may crowd out natives and reduce their incentive to choose a law-abiding path. In their contribution to this volume, Brian Bell and Stephen Machin conclude that empirical evidence on the effect of immigration on crime is scanty, but suggestive that immigration by groups that have a weak connection to the labor market may increase property-crime rates.

In most models of criminal activity, the perpetrators are not organized, and unconcerned about their individual effect on public or private control systems. But of course some criminal activity is organized and hence subject to the management of whatever system of control exists within the criminal organization. Economists have not yet paid much attention to criminal gangs, with the partial exception of the Mafia (Reuter 1983). Nobel Laureate Thomas Schelling (1967) was the first to point out that the business of organized crime - the Mafia -- is not to provide illicit goods and services to the public, but rather to gain control and extort money from such providers. The resulting cartel position in the provision of vice and other contraband actually creates an incentive to restrict supply in order to preserve prices (Buchanan 1973), which may seem like a good outcome from the public interest perspective, despite the lethal tactics used to acquire and preserve that monopoly. One problem is that the wealth and power of the organization is used to corrupt public officials as well limit the activities of the private suppliers of vice. In his contribution to this volume, Paulo Pinotti provides empirical evidence that the influence of the Mafia in some areas of Italy extends deep into the political process, affecting the quality of candidates who run for office as well as the amount budgeted for easily corrupted public-works projects.

Among the feedback effects that have figured importantly in crime research is through the political process, which translates public concern about crime into resource allocation to the criminal justice system. The influence of crime rates on police budgets is well documented, as shown in the chapter by Paolo Buonanno and Giovanni Mastrobuoni. Interestingly, they find that police hiring in the United States is more responsive to changes in crime than is true in Italy, 
where hiring and deployment decisions are nationally centralized and subject to perhaps more red tape than in the United States. Another potential mechanism that links policing to crime is the process of learning and innovation. Priks observes that the police response to hooliganism by soccer fans has evolved in some jurisdictions, where the police have learned that targeting individuals for arrest and prosecution is a more effective strategy than the traditional crowdcontrol approach (using water cannons and the like). Despite its evident advantages, this selective approach has not yet been adopted everywhere.

The learning and innovation process in policing may well be subject to political pressure brought by public concern about crime, just as is the resource allocation process. Rodrigo Soares and Igor Viveiros describe the effort to reform policing in Minas Gerais, the second largest state in Brazil, under pressure from a surge in crime rates beginning in the mid-1990s. The police functions in Minas Gerais (as in other states) are divided between the Military Police, responsible for patrol and the immediate response to crime, and the Civil Police, which is responsible forinvestigations and general assistance to the judiciary. The lack of coordination between these two forces reduces effectiveness and efficiency. The government of Minas Gerais was able to overcome bureaucratic inertia and institute a plan of integration and improved communication beginning in 2005. The results for crime control appear to be favorable.

\section{Concluding thoughts}

The economists are here to stay in the study of crime, the criminal justice system, and crime prevention. The economists have brought with them a strong presumption that criminal behavior can be usefully modeled using the same conceptual apparatus that economic science has developed for risky decision making, labor supply, consumer and firm behaviour, and even market structure and performance. Criminal law and crime-prevention programs can be evaluated using the same normative apparatus that is routinely applied to education, health, and environmental regulation. Of course the rules of statistical inference require no modifications. In short, crime is another choice, as Gary Becker suggested in 1968, and crime research using standard economic methods can be productive.

Our entrance into this arena, led by Gary Becker and Thomas Schelling in the late 1960s, did not lead to immediate assimilation into the field of criminology, and in fact the differences in agenda and conceptual frameworks initially produced a good deal of antagonism. But it is fair to say that the trend is toward greater mutual influence and respect. The topics and references of chapters in this volume reflect the increasingly eclectic approach of economists, and increasing respect for contributions by others social scientists. Those trends are welcome, and offer hope for efficient development of a sturdy base of evidence that can be used for policy design and evaluation. 


\section{$\underline{\text { References }}$}

Ayres, Ian and Steven Levitt (1998) Measuring Positive Externalities from Unobservable Victim Precaution: An Empirical Analysis of Lojack, Quarterly Journal of Economics, 1998, 113(1), pp. 43-77.

Becker, Gary (1968) Crime and Punishment: An Economic Approach, Journal of Political Economy, 76 (2), 175-209

Blumstein Alfred, Jacqueline Cohen and Daniel Nagineds, (1978) Deterrence and Incapacitation: Estimating the Effects of Criminal Sanctions on Crime Rates, Report of the Panel of Deterrence and Incapacitation, Washington, D.C. : National Academy of Sciences

Braga, Anthony A., David Kennedy, and Anne Piehl (1997)"Controlling Violent Offenders Released to the Community: An Evaluation of the Boston Reentry Initiative" Journal of Research in Crime and Delinquency, 46(4), 411-436.

Buchanan, James M. (1973), 'A Defense of Organized Crime', in Andreano, Ralph and Siegfried, John J. (eds), The Economics of Crime, Cambridge, Schenkman.

Buonanno, Paulo, Francesco Drago, Roberto Galbiati and Giulio Zanella (2011) Crime in Europe and the United States: dissecting the 'reversal of misfortunes', Economic Policy, 26(67), 347-385.

Carr-Hill, Roy A. and Stern Nicholas (1973) An econometric model of the supply and control of recorded offences in England and Wales. Journal of public economics, 2(4). 289-318.

Cook, Philip J. 1977, "Punishment and Crime: A Critique of Recent Findings on the Preventive Effects of Punishment" Law and Contemporary Problems, Winter 1977, 164-204

Cook, Philip J. 1986 "The Demand and Supply of Criminal Opportunities" in Michael Tonry and Norval Morris, eds. Crime and Justice: An Annual Review of Research, Vol. 7, University of Chicago Press, 1-28.

Cook Philip J. and JohnLaub (2002) "After the Epidemic: Recent Trends in Youth Violence in theUnited States" in Michael Tonry ed. Crime and Justice: A Review of Research, Chicago: University of Chicago Press.

Cook, Philip J, Jens Ludwig, and Justin McCrary eds.(2011)Controlling Crime: Strategies and Tradeoffs, Chicago: University of Chicago Press 
Cook, Philip J,, Jens Ludwig, Sudhir Venkatesh, and Anthony A. Braga (2007) "Underground Gun Markets" The Economic Journal, 117 (524), 588-618

Cook, Philip J. and John MacDonald. 2011.

Di Tella, Raphael, Sebastian Edwards and Ernesto Schargrodsky eds.(2010) The Economics of Crime: Lessons for and from Latin America. Chicago: University of Chicago Press.

Dodge, Kenneth. 2008. "Framing Public Policy and Prevention of Chronic

Violence in American Youths" American Psychologist 63(7), October, 573-590.

Ehrlich, Isaac (1973) Participation in Economic Activity: A Theoretical and Empirical Investigation, Journal of Political Economy, 81 (3), 521-563

Grogger, Jeffrey (1995) The Effect of Arrests on the Employment and Earnings of Young Men, Quarterly Journal of Economics 110 (1), 51-71.

Hjalmarsson, Randi, Helena Holmlund and Matthew J. Lindquis (2012) The Effect of Education on Criminal Convictions and Incarceration: Causal Evidence From Micro-data, Stockholm University mimeo.

Kling, Jeffrey R. (2006) Incarceration Length, Employment, and Earnings, The American Economic Review 96 (3), 863-76.

Levitt, Steven. (1996) The Effect of Prison Population Size on Crime Rates: Evidence from Prison Overcrowding Litigation, Quarterly Journal of Economics,111(2), pp. 319-51.

Levitt, Steven (2004) "Understanding Why Crime Fell in the 1990s: Four Factors that Explain the Decline and Six that Do Not"Journal of Economic Perspectives 18, (1 Winter, 163190.

Levitt, Steven and Stephen Dubner(2005). Freakonomics: A Rogue Economist Explores the Hidden Side of Everything, William Morrow.

Lochner, Lance and Enrico Moretti (2004) The Effect of Education on Crime: Evidence From Prison Inmates, Arrests and Self-Reports,American Economic Review 94, 155-189.

Machin, Stephen and Olivier Marie (2011) Crime and Police Resources: The Street Crime Initiative, Journal of the European Economic Association, 9 (4), 678-701.

Machin, Stephen, Olivier Marie, and Suncica Vujic (2011) The Crime Reducing Effect of Education, The Economic Journal 121 (552), 463-484.

Muncie, John (2005) The Globalization of Crime Control - the Case of Youth and Juvenile Justice: Neo-liberalism, Policy Convergence and International Conventions, Theoretical Criminology, 9, 35-64. 
Reuter, Peter (1983)Disorganized Crime: The Economics of the Visible Hand,Cambridge: MIT Press.

Schelling, Thomas (1971)What Is the Business of Organized Crime? Journal of Public Law, 20(1), 71-84.

Sjoquist, David L. (1973) Property Crime and Economic Behavior: Some Empirical Results,American Economic Review, 63(3), 439-446.

Wilson, James Q. 1975. Thinking About Crime New York: Basic Books. 